\title{
Microbial, Physical and Sensory Properties of Three Novel Yogurt Flavors: Molasses, Mulberry and Amaretto
}

\author{
Wannee Tangkham ${ }^{1} \&$ Frederick LeMieux ${ }^{1}$ \\ ${ }^{1}$ School of Agricultural Sciences, McNeese State University, Lake Charles, LA, USA \\ Correspondence: Wannee Tangkham, School of Agricultural Sciences, McNeese State University, Lake Charles, \\ LA, USA. E-mail: wtangkham@mcneese.edu
}

Received: February 25, 2017

Accepted: March 20, 2017 Online Published: April 24, 2017

doi:10.5539/jfr.v6n3p65

URL: https://doi.org/10.5539/jfr.v6n3p65

\begin{abstract}
Many consumers incorporate yogurt into their diet as a healthy alternative to other food choices. Providing a variety of flavor choices to the yogurt consumer is important to maintain eating satisfaction. The objective of this study was to evaluate specific attributes of three novel yogurt flavors. These flavors, sweetened with low calorie stevia, include molasses, amaretto and mulberry. Through sensory testing, each flavor was evaluated for consumer product acceptance and purchase intent. Additionally, the yogurt products were assayed for certain physicochemical characteristics and microbial counts. Using a 9-point hedonic scale, fifty-eight participants (23 males and 35 females) evaluated the yogurt flavors for acceptability of appearance, color, flavor, sweetness, sourness, texture and overall liking. Physicochemical characteristics were evaluated for $\%$ moisture content, $\mathrm{pH}$ value, color ( $\mathrm{L}^{*}, \mathrm{a}^{*}$ and $\mathrm{b}^{*}$ values) and lipid oxidation (thiobarbituric acid-reactive substances (TBARS) protocol) every 7 days for 28 days. Through plating techniques, yogurt was assayed for two microbial counts: Escherichia coli and Staphylococcus aureus every 7 days for 28 days. Overall liking scores from the hedonic analysis indicate that mulberry flavor was the most desirable (5.67), followed by amaretto (5.32), and molasses (5.07). From the acceptability, mulberry yogurt scored the highest at $70.69 \%$. From the purchase intent questionnaires, amaretto yogurt scored the highest at $44.83 \%$. In general, there were no outstanding differences in the physiochemical characteristics among the three yogurts tested. However, \% moisture content and L* values (lightness) increased in all samples over the 28 days of storage. The TBARS values were higher in molasses flavor at $5.84 \mathrm{mg} \mathrm{MDA} / \mathrm{kg}$. No E. coli or $S$. aureus were detected. This study provides valuable insight into the quality, safety, shelf-life and consumer acceptance of the three novel yogurt flavors.
\end{abstract}

Keywords: novel yogurt flavors, sensory testing, pathogenic microorganisms

\section{Introduction}

Yogurt is a popular product consumed for millennia (Tamine \& Deeth, 1980; Kurmann, 1984; Tamime \& Robinson, 1985). Cultured yogurt is milk fermented with lactic acid-producing bacteria such as Lactobacillus delbrueckii subsp. bulgaricus and Streptococcus thermophiles. The yogurt industry has a high potential in expanding sales from $\$ 6.2$ billion in 2010 to $\$ 7.7$ billion in 2015 (Statistic, 2016).

Flavor perception is a complex phenomenon and consists of odor, taste, and somatosenses (Reineccius, 2006). Flavors commonly added to yogurt include vanilla, coffee, fruits and nuts (Tamime \& Robinson, 2007). Strawberry is the most popular (Routray \& Mishra, 2011). Sweeteners added include sugar, honey, aspartame, and stevia.

Black strap molasses is a natural flavor that has a higher content of antioxidants compared to brown sugar, which is partly refined sugar. Black strap molasses possess higher nutritional benefits, including $14-20 \%$ of the daily values of iron, potassium and calcium. Amaretto is an almond-flavored liqueur that originated in the Saronno region of Italy. It's characteristic reddish-brown color is a central attribute recognized and valued by the customer (Castañeda-Olivares, Pless, \& González-Jasso, 2010). Black mulberry (Morus nigra L.) fruit is blackish-red and sweet-sour flavored. Some components include sugars, organic acids, tannins and anthocyanins (Kong, S. Chia, Goh, F. Chia, \& Brouillard, 2003). As antioxidants, anthocyanins can function as hydrogen donors to free radicals and capture metallic ions to prevent oxidation (Kong, S. Chia, Goh, F. Chia, \& Brouillard, 2003). It is thought that these molecules might reduce the risk cancer, diabetes, and coronary thrombosis (Lazze et al., 2004). Mulberry fruit also contains phenolic compounds that might prevent inflammation and hinder the 
growth of bacteria and viruses (G. Duthie, J. Duthie, \& Kyle, 2000). Studies have shown that mulberry fruit contains quercetin, which is a flavonoid with anti-inflammatory activity (Manach, Mazur, \& Scalbert, 2005). Therefore, quercetin might reduce the risk of heart disease, high blood pressure and blood clots (Manach, Mazur, \& Scalbert, 2005).

Competition within the market provides pressure for innovation. This is the particularly true in the development of new and novel yogurt flavors. The objective of this study was to evaluate specific attributes of molasses, amaretto and mulberry yogurt flavors sweetened with stevia.

\section{Method}

\subsection{Preparation of Three Yogurt Flavors}

Three ingredients were obtained locally in Lake Charles, Louisiana for flavoring. Mulberry fruits (Morus alba) were collected in the wild, molasses and amaretto were purchased from local markets. Yogurt was prepared with cow's whole milk (86.95\%), plain yogurt containing Lactobacillus acidophilus $(8.70 \%)$, stevia $(2.61 \%)$ and experimental flavor (1.74\%). Milk was heated at $60^{\circ} \mathrm{C}$ for $5 \mathrm{~min}$, before being cooled to inoculation temperature $\left(42^{\circ} \mathrm{C}\right)$. Plain yogurt and stevia were added to the milk solution. The samples were transferred to sterilized containers and incubated for 4 hours at $42^{\circ} \mathrm{C}$. Samples were stored at $3^{\circ} \mathrm{C}$ for future physicochemical, microbiological and sensory analyses. Each sample was analyzed for $\mathrm{pH}$, moisture content, color $\left(\mathrm{L}^{*}, \mathrm{a}^{*}\right.$, and $\mathrm{b}^{*}$ values), lipid stability (TBARS), Escherichia coli (E.coli) and Staphylococcus aureus (S. aureus) at $7 \mathrm{~d}$ intervals for $28 \mathrm{~d}$. Additionally, each sample was evaluated for consumer product acceptance and purchase intent.

\section{$2.2 \mathrm{pH}$ Test}

Each yogurt treatment was replicated three times and evaluated for $\mathrm{pH}$ with a probe electrode portable meter (Model 2000 VWR Scientific) results are expressed as the mean and standard error of the mean (SEM). Calibration of the $\mathrm{pH}$ meter was accomplished using $\mathrm{pH} 7$ and $\mathrm{pH} 4$ standardization buffers before use.

\subsection{Moisture Content}

Moisture content was determined according to the design method of the Association of Official Analytical Chemists (AOAC, 2000). Crucibles were heated in the oven at $102^{\circ} \mathrm{C}$ for $3 \mathrm{~h}$ and transferred to a desiccator to cool and record dry crucible weight. Each $3 \mathrm{~g}$ yogurt treatment with three replications was weighed and dried in a hot air oven (Model 26 Precision Thelco) at $102^{\circ} \mathrm{C}$ for $24 \mathrm{~h}$. After drying, crucibles were moved to the desiccator to cool and obtain dry sample weight. The total moisture content was determined by dividing the difference between the initial weight (IW) and dry weight (DW) by initial weight.

$$
\text { [(IW-DW)/IW] }
$$

\subsection{Color Test}

Color was measured at three different locations, with three replications, on the surface of each yogurt treatment with a Minolta spectrophotometer (Model CR-10 portable) using an $8 \mathrm{~mm}$ aperture, $10^{\circ}$ observer angle, D65 illuminant source in terms of $\mathrm{L}^{*}($ white $=100$, black $=0), \mathrm{a}^{*}(+40=$ red, $-40=$ green $), \mathrm{b}^{*}(+40=$ yellow, $-40=$ blue). The colorimeter was calibrated to a white plate before use.

\subsection{TBARS Test}

The thiobarbituric acid-reactive substances (TBARS) method (Tarladgis, Watts, Younathan, \& Jr. Dugan, 1964) was used to measure lipid oxidation. A fifteen gram of each yogurt with three replications was blended with 30 $\mathrm{mL}$ of trichloroacetic acid solution. The sample solution was filtered through Whatman No. 1 filter paper. Five $\mathrm{mL}$ aliquots of the filtrate were transferred to separate test tubes (in duplicate) and mixed with $5 \mathrm{~mL}$ of $0.02 \mathrm{M}$ TBA. The mixture was vigorously agitated in a vortex and was heated in a boiling water bath $\left(100^{\circ} \mathrm{C}\right)$ for $45 \mathrm{~min}$ to develop a pink color. After cooling the reaction mixture under running water the absorbance was determined at $530 \mathrm{~nm}$ using a Beckman Du-640 spectrophotometer against a blank containing $5 \mathrm{~mL}$ of distilled water and $5 \mathrm{~mL}$ of TBA reagent. The TBA value used to express the results were calculated from standard curves and known dilutions of tetraethoxypropane (TEP) and the results were expressed as mg malondialdehyde (MDA) $/ \mathrm{kg}$ yogurt.

\subsection{Microbial Counts}

The microorganisms were determined following the standards of the AOAC (2000). For this study, yogurt was assayed for two undesirable microorganisms: E.coli and S. aureus. The following protocol was used for $E$. coli and S. aureus. Buffered peptone water (BPW) was added as a diluent option for serial dilutions. Following $3 \mathrm{M}^{\mathrm{TM}}$ Petri film plating instructions, each $1.0 \mathrm{ml}$ of sample with three replications was aseptically transferred and was plated on $3 \mathrm{M}^{\mathrm{TM}}$ petrifilm to determine the enumeration (log CFU/g) of E.coli and S. aureus. All samples were 
incubated for $24-48$ hours at $37^{\circ} \mathrm{C}$. Data were collected from countable plates (30-300 colonies per plate). The counted colonies were reported as $\mathrm{CFU} / \mathrm{g}$.

\subsection{Sensory Evaluation}

All participants were volunteers solicited through advertisements posted in the Agricultural Sciences building on the McNeese State University Campus. The test room was illuminated with cool, natural, fluorescent lights. The participants were presented with three digit randomly coded samples. Each preparation was evaluated for consumer product acceptance and purchase intent. Using a 9-point hedonic scale, fifty-eight untrained participants (23 males and 35 females) evaluated the yogurt flavors for acceptability of appearance, color, flavor sweetness, sourness, texture and overall liking $(9=$ like extremely, $8=$ like very much, $7=$ like moderately, $6=$ like slightly, 5 = neither like nor dislike, $4=$ dislike slightly, $3=$ dislike moderately, $2=$ dislike very much, $1=$ dislike extremely). Participants also completed an acceptability and purchase intent questionnaire. The participants were also required to cleanse their palates with water between tasting the samples

\subsection{Statistical Analysis}

The Proc GLM procedures of SAS windows (SAS, 2003) were used to evaluate the significance of differences of the obtained data. The PDIFF option of LSMEANS was employed to determine significance among treatments. All data are presented as means with standard deviation (SD) and a significance level of $\mathrm{P}<0.05$ was used for statistical analysis of means from treatments.

\section{Results and Discussion}

\section{$3.1 \mathrm{pH}$}

Over the 28 day experimental period, changes in $\mathrm{pH}$ over each treatment profile exhibited significant differences $(\mathrm{P}<0.05)$. The initial $\mathrm{pH}$ values of yogurt treatments were 4.43-4.46 (Figure 1) which is similar to earlier findings (Choi, Jin, Yang, Lee, \& Huh, 2016). Our results showed that $\mathrm{pH}$ value decreased in all samples during the days 0 to 21 and increased from days 21 to 28 . Specifically, mulberry treatment had the lowest $\mathrm{pH}$ value $(\mathrm{P}<0.05)$ at 4.39 after refrigerated storage at $3^{\circ} \mathrm{C}$ for 28 days. This result suggests that mulberry had the general effect to reduce the acidity of the yogurt. This due to the post acidification was accelerated and storage stability was reduced (Kim, Ren, \& Dunn, 1999; Shah, 2000).

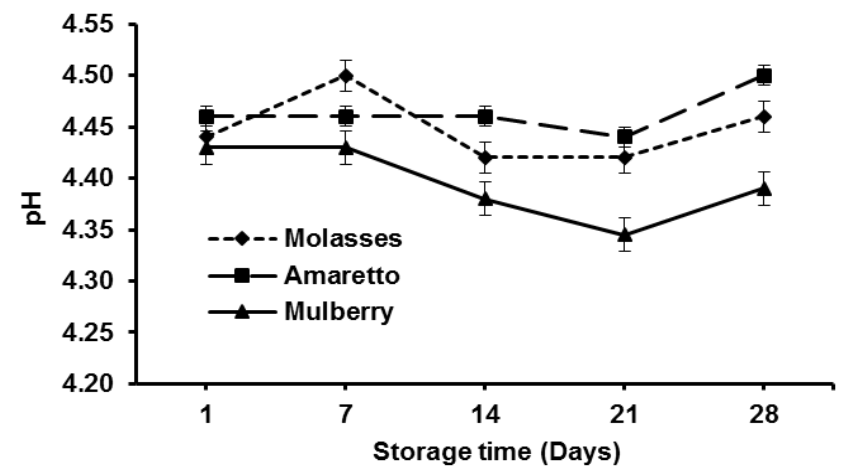

Figure 1. Least squares means for $\mathrm{pH}$ values of three yogurt flavors stored at $3^{\circ} \mathrm{C}$ for 28 days. $\mathrm{SEM}=0.008$

\subsection{Moisture Content}

Moisture content of yogurt was significantly $(\mathrm{P}<0.05)$ affected by molasses, amaretto and mulberry flavors up to $28 \mathrm{~d}$ storage (Figure 1). The average initial of moisture content of three yogurt flavors were $82.66-85.19 \%$. The initial water content of each of the three treatments increased slightly $(\mathrm{P}<0.05)$ during the course of the experiment and this result was similar to the study of (Nayla, Gilani, \& Naheed, 2008). Specifically, a respective increase of $40.7 \%, 13.93 \%$, and $45.36 \%$ for molasses, amaretto and mulberry was detected over 28 days. This increase in moisture content may be due to the gain of moisture/water from the internal atmosphere of the refrigerator during storage period. Therefore, packaging might become a critical factor in the commercial market for yogurt. 


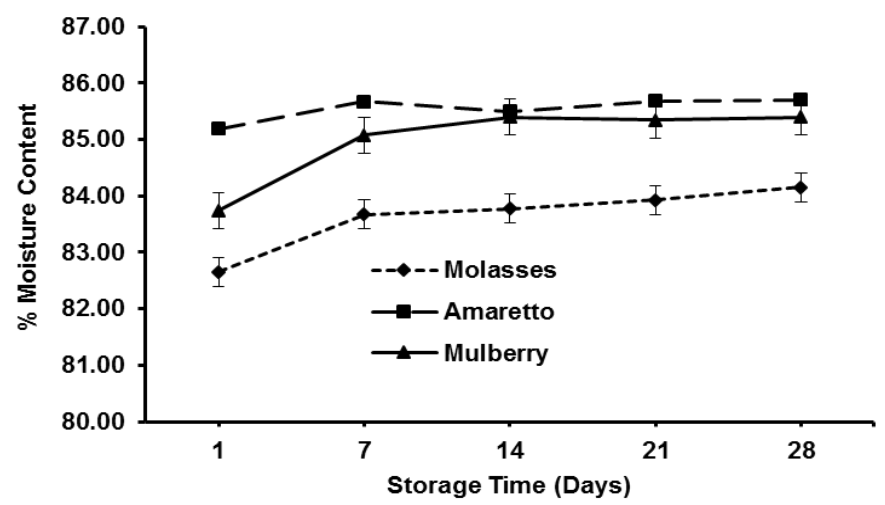

Figure 2. Least squares means for moisture content $(\%)$ of three yogurt flavors stored at $3^{\circ} \mathrm{C}$ for 28 days. $\mathrm{SEM}=$ 0.33

\subsection{Color Test}

Increasing changes in lightness $\left(\mathrm{L}^{*}\right)$ values represent greater light dispersion and increased lightness and is correlated with changes in yogurt, especially casein protein destruction. This is likely due to protein denaturation (García-Pérez et al., 2005). Results from the present study indicated that no significant differences occurred in the $\mathrm{L}^{*}$ values among the three treatments during each week of the storage period $(\mathrm{P}>0.05)$ (Table 1$)$. These results suggest that molasses, amaretto and mulberry flavors used in this study did not significantly affect the yogurt product in term of lightness. These results are similar to those found by Hyo, Hye, Jun, and Yoon (2013).

There was a significant difference $(\mathrm{P}<0.05)$ observed in $\mathrm{a}^{*}$ values between treatments. Redness $\mathrm{a}^{*}$ values for all samples decreased $(\mathrm{P}<0.05)$ with storage time. The nominal values between the three treatments were small (Table 1). Therefore, color transition among the three different treatments was similar. This suggests that flavors has little impact on initial color or color as it changes through time.

Yellowness is measured in terms of positive $\mathrm{b}^{*}$ values. The molasses flavor had the highest $(\mathrm{P}<0.05)$ yellowness $b^{*}$ value at 13.15 throughout 21 days of storage. This result showed that molasses flavor appeared to give the yogurt higher yellowness than amaretto and mulberry treatments.

Table 1. HunterLab L*, $\mathrm{a}^{*}$, and $\mathrm{b}^{*}$ values of three yogurt flavors stored at $3^{\circ} \mathrm{C}$ for 28 days.

\begin{tabular}{lllllll}
\hline Parameter & Treatment & \multicolumn{5}{c}{ Storage time (d) } \\
\cline { 3 - 7 } & & 1 & 7 & 14 & 21 & 28 \\
\hline $\mathrm{L}^{*}$ & Molasses & $43.70^{\mathrm{a}}$ & $54.78^{\mathrm{a}}$ & $58.00^{\mathrm{a}}$ & $56.95^{\mathrm{a}}$ & $53.63^{\mathrm{a}}$ \\
& Amaretto & $54.05^{\mathrm{b}}$ & $56.25^{\mathrm{a}}$ & $58.35^{\mathrm{ab}}$ & $59.40^{\mathrm{b}}$ & $57.53^{\mathrm{a}}$ \\
& Mulberry & $49.80^{\mathrm{ab}}$ & $51.05^{\mathrm{a}}$ & $51.70^{\mathrm{ac}}$ & $47.55^{\mathrm{ab}}$ & $53.70^{\mathrm{a}}$ \\
\hline $\mathrm{a}^{*}$ & Molasses & $1.15^{\mathrm{a}}$ & $1.30^{\mathrm{a}}$ & $1.35^{\mathrm{a}}$ & $0.60^{\mathrm{a}}$ & $0.30^{\mathrm{a}}$ \\
& Amaretto & $2.20^{\mathrm{b}}$ & $3.08^{\mathrm{a}}$ & $1.80^{\mathrm{a}}$ & $1.70^{\mathrm{b}}$ & $1.50^{\mathrm{a}}$ \\
& Mulberry & $2.65^{\mathrm{a}}$ & $2.78^{\mathrm{a}}$ & $2.45^{\mathrm{a}}$ & $1.55^{\mathrm{ab}}$ & $1.97^{\mathrm{a}}$ \\
\hline $\mathrm{b}^{*}$ & Molasses & $12.50^{\mathrm{a}}$ & $13.63^{\mathrm{a}}$ & $14.55^{\mathrm{a}}$ & $13.45^{\mathrm{a}}$ & $13.17^{\mathrm{a}}$ \\
& Amaretto & $6.05^{\mathrm{b}}$ & $5.45^{\mathrm{a}}$ & $6.25^{\mathrm{b}}$ & $5.85^{\mathrm{b}}$ & $5.47^{\mathrm{ab}}$ \\
& Mulberry & $2.25^{\mathrm{ab}}$ & $2.53^{\mathrm{a}}$ & $4.50^{\mathrm{ac}}$ & $3.40^{\mathrm{ab}}$ & $3.67^{\mathrm{bc}}$ \\
\hline
\end{tabular}

a,b,c LSMeans with different superscripts within a row is significantly different $(\mathrm{P}<0.05)$.

\subsection{Lipid Stability (TBARS)}

The lipid oxidation of three flavor yogurts were measured using the TBARS assay (milligrams malonaldehyde per kilogram of sample). There was a significant effect $(\mathrm{P}<0.05)$ in TBARS values of three flavor yogurts throughout the 28-day storage period (Figure 3). The TBARS values were higher in molasses flavor at $5.84 \mathrm{mg}$ $\mathrm{MDA} / \mathrm{kg}$. This is probably due to the higher level of sucrose in molasses could interfere with the reaction 
between TBA and MDA and this result was similar previous finding (Fernandez, Perez-Alvarez, \& Fernandez-Lopez, 1997; Wang, Pace, Dessai, Bovell-Benjamin, \& Phillips, 2002).

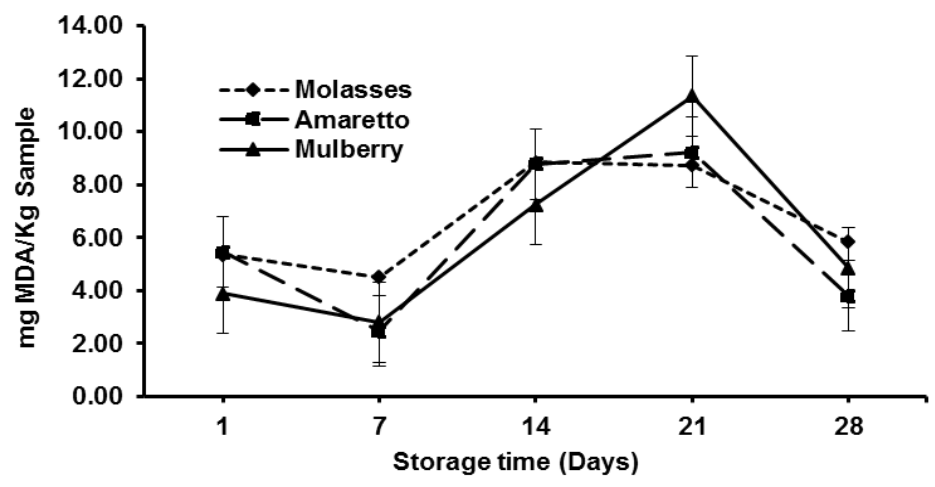

Figure 3. TBARS (thiobarbituric acid-reactive substances) values of yogurt stored at $3^{\circ} \mathrm{C}$ for 28 days. $\mathrm{SEM}=$ 0.014

\subsection{Microbial Counts}

In this study, yogurt was assayed for E.coli and S. aureus. Our study found that there was no E.coli or S. aureus detected throughout the $28 \mathrm{~d}$ of storage at $3^{\circ} \mathrm{C}$. This suggested that the three yogurt flavors had no effect on the microbial counts. However, Massa, Altieri, Quaranta, \& Pace (1997) and Ogwaro, Gibson, Whitehead, \& Hill (2002) detected the counts of E.coli during storage. Benkerroum, Oubel, \& Mimoun (2002) also detected the numbers of $S$. aureus in yogurt product. The difference results might be due to the preparation of yogurt.

\subsection{Sensory Evaluation}

\subsubsection{Demographic Information}

The two largest age groups (18-24 and 45-54 years old) accounted for $63.8 \%$ of the total. Female participants $(60.34 \%)$ exceeded males $(39.66 \%)$. The majority of the consumers' race and ethnicity backgrounds were Caucasian (75.86\%), and African-American (12.07\%). The largest group of participants had graduated college or completed some college (75.86) and the second largest group, had only high school education (24.14\%). A large percentage $(25.86 \%)$ of the consumers in this study had a household income under $\$ 9,999$. This fact is not surprising as most of the consumers were college-aged.

\subsubsection{Product Information}

The number/percentage of consumers who consume yogurt products is presented in Table 2. Most of the consumers reported that they do consume yogurt based products. In fact, $56.9 \%$ of consumers reported that they consume low fat yogurts and they consumed low-fat sugar-free yogurt products at $69 \%$. However, the number of consumers who consume sugar-free yogurts is lower, with only $37.9 \%$ responding positively.

According to consumers responses, $56.9 \%$ indicated that mouthfeel was the majority of responses indicated that taste was the most important attribute (Table 2). The second most important attribute was nutrition and aroma of the product (17.2\%). Color is also an important quality attribute for a yogurt product, with $5.2 \%$ of consumers choosing this option.

The consumer choice of flavor is also an important factor of this study (see Table 2). The most preferred flavor was strawberry (55.2\%). However, $17.2 \%$ of people did report that a cherry flavor would be desirable for this type of product. The peach and lime flavors were preferred by 12.1 and $6.9 \%$ of consumers, respectively. Only $5.2 \%$ of participants reported pineapple flavor. The consumers were also asked whether or not they would purchase the product if it contains stevia as sugar substitution. This question was important to determine consumer perceptions before they tasted the product (Table 2). Also, they played a role in determining whether consumer perceptions and purchase intent changed after tasting the product. Interestingly enough, most of $65.5 \%$ the consumers responded that they would purchase a yogurt contains stevia. 
Table 2. Consumer product questionnaires

\begin{tabular}{lll}
\hline Yogurt & Number/Percentage & Number/Percentage \\
\hline & Yes & No \\
\hline Do you normally eat yogurts that are low in fat? & $33 / 56.9$ & $25 / 43.1$ \\
\hline Do you normally eat yogurts that are sugar-free? & $22 / 37.9$ & $36 / 62.1$ \\
\hline $\begin{array}{l}\text { Have you purchased or consumed low-fat sugar-free yogurt } \\
\text { products? }\end{array}$ & $40 / 69.0$ & $18 / 31.0$ \\
\hline $\begin{array}{l}\text { Would you purchase these products if they contain } \\
\text { health-promoting ingredient such as stevia? }\end{array}$ & $38 / 65.5$ & $20 / 34.5$ \\
\hline How often do you buy yogurt? & & \\
More than once a week & $4 / 6.9$ & \\
Once a week & $13 / 22.4$ & \\
Twice a month & $10 / 17.2$ & \\
Once a month & $11 / 19.0$ & \\
Very rarely & $15 / 25.9$ & \\
Never & $5 / 8.6$ & \\
\hline
\end{tabular}

What is the most important quality attribute that you want in this type of product?

$\begin{array}{ll}\text { Color } & 3 / 5.2 \\ \text { Mouthfeel } & 33 / 56.9 \\ \text { Taste } & 2 / 3.5 \\ \text { Nutrition } & 10 / 17.2 \\ \text { Aroma } & 10 / 17.2\end{array}$

\begin{tabular}{ll}
\hline What is your most preferred flavor in yogurts? & \\
Grape & $3 / 0$ \\
Orange & $4 / 6.9$ \\
Lime & $32 / 55.2$ \\
Strawberry & $10 / 17.2$ \\
Cherry & $7 / 12.1$ \\
Peach & $2 / 3.4$ \\
Pineapple & \\
Which taste do you prefer most for yogurt products? & $31 / 53.45$ \\
Sweeter and less sour & $5 / 8.62$ \\
More sour and less sweet sour & $22 / 37.93$ \\
Sweet / sour equally & \\
\hline
\end{tabular}

\subsubsection{Consumer Acceptability}

Using the hedonic scale, participants evaluated the yogurt for appearance, color, flavor, sweetness, sourness, mouthfeel and overall liking (Table 3). With reference to flavor, scores were different between molasses and amaretto treatments $(\mathrm{P}<0.05)$. However, appearance, color, sweetness, sourness, mouthfeel and overall liking, scores among all three treatments statistically were not significantly different $(\mathrm{P}>0.05)$ (Table 3$)$. Specifically, mulberry flavor was the most desirable (5.67), followed by amaretto (5.32), and molasses (5.07) (Table 3). These results suggest that mulberry, amaretto and molasses can be viable alternatives to yogurt flavor. 


\subsubsection{Acceptability and Purchase Intent}

Each yogurt flavor was evaluated separately using a 2-point hedonic scale (yes/no). Using the acceptability and purchase intent questionnaire, consumers evaluated the yogurt for acceptability, whether or not they would purchase the product and whether or not they would purchase the product if it claimed to contain stevia, low calorie, which can reduce health issues including obesity, diabetes and heart problems. The percent (\%) of positive responses for the aforementioned questions is shown in Table 4. All three yogurt treatments received similar scores with respect to acceptability and purchase intent $(\mathrm{P}>0.05)$.

From the acceptability, mulberry yogurt scored the highest at $70.69 \%$. These results correspond directly to the mean consumer acceptance scores, where the mulberry flavor had the highest overall liking. From the purchase intent questionnaires, amaretto yogurt scored the highest at $44.83 \%$ (Table 4). Finally, with respect to whether or not the consumers would purchase the product if it claimed to contain low calorie, both mulberry and molasses yogurts received similar scores at $41.38 \%$. However, amaretto yogurt scored the lowest at 39.66\% (Table 4).

Table 3. Consumer acceptance scores for sensory attributes and overall liking of three yogurt flavors

\begin{tabular}{lcccc}
\hline Properties & Molasses & Amaretto & Mulberries & SEM \\
\hline Appearance & $5.74^{\mathrm{a}}$ & $6.37^{\mathrm{a}}$ & $6.30^{\mathrm{a}}$ & 0.22 \\
Color & $6.00^{\mathrm{a}}$ & $6.82^{\mathrm{a}}$ & $6.07^{\mathrm{a}}$ & 0.22 \\
Flavor & $4.91^{\mathrm{a}}$ & $5.75^{\mathrm{b}}$ & $5.36^{\mathrm{ab}}$ & 0.28 \\
Sweetness & $5.14^{\mathrm{a}}$ & $5.65^{\mathrm{a}}$ & $5.04^{\mathrm{a}}$ & 0.81 \\
Sourness & $5.16^{\mathrm{a}}$ & $4.95^{\mathrm{a}}$ & $5.49^{\mathrm{a}}$ & 3.73 \\
Mouthfeel & $5.56^{\mathrm{a}}$ & $5.37^{\mathrm{a}}$ & $5.65^{\mathrm{a}}$ & 0.26 \\
Overall liking & $5.07^{\mathrm{a}}$ & $5.32^{\mathrm{a}}$ & $5.67^{\mathrm{a}}$ & 0.36 \\
\hline
\end{tabular}

a,b LSMeans with different superscripts within a row is significantly different $(\mathrm{P}<0.05)$.

Table 4. Acceptability and purchase intent questionnaire $(\mathrm{N}=58)$ of three yogurt flavors

Molasses Number/Percentage Amaretto Number/Percentage Mulberries Number/Percentage

\begin{tabular}{lrrr}
\hline Acceptable & & $39 / 67.24^{\mathrm{a}}$ & \\
Yes & $34 / 58.62^{\mathrm{a}}$ & $19 / 32.76^{\mathrm{a}}$ & $17 / 70.69^{\mathrm{a}}$ \\
No & $24 / 41.38^{\mathrm{a}}$ & & \\
Purchase & & $26 / 44.83^{\mathrm{a}}$ & $23 / 39.66^{\mathrm{a}}$ \\
Yes & $20 / 34.48^{\mathrm{a}}$ & $32 / 55.17^{\mathrm{a}}$ & $35 / 60.34^{\mathrm{a}}$ \\
No & $38 / 65.52^{\mathrm{a}}$ & & \\
Purchase + health claim & & \\
Yes & $24 / 41.38^{\mathrm{a}}$ & $23 / 39.66^{\mathrm{a}}$ & $24 / 41.38^{\mathrm{a}}$ \\
No & $34 / 58.62^{\mathrm{a}}$ & $35 / 60.34^{\mathrm{a}}$ & $34 / 58.62^{\mathrm{a}}$ \\
\hline
\end{tabular}

${ }^{\mathrm{a}}$ Row is not significantly different $(\mathrm{P}>0.05) .{ }^{1}$ Low calorie stevia

\section{Conclusions}

The results of this study provide valuable insight into the quality, safety, shelf-life and consumer acceptance of the three novel yogurt flavors. Specifically, participants rated all three treatments similarly with respect to appearance, color, sweetness, sourness, mouthfeel and overall liking. Additionally, all three treatments received positive participant ratings with respect to acceptability and purchase intent with and without health claims. Therefore, three yogurt flavors might be a marketable alternative to original yogurt.

\section{References}

Association of Official Analytical Chemists (AOAC). (2000). Official methods of analysis (17th ed.). Maryland, MD: Gaithersburg.

Benkerroum, N., Oubel, H., \& Mimoun, L. B. (2002). Behavior of Listeria monocytogenes and Staphylococcus aureus in yoghurt fermented with a bacteriocin-producing thermophilic starter. Journal of Food Protection, 
65, 799-805. https://doi.org/10.4315/0362-028X-65.5.799

Castañeda-Olivares, F., Pless, R. C., \& González-Jasso, E. (2010). Effect of light and sweeteners on color in an amaretto-type liqueur. Journal of Food Science, 75(9), C766-C773. https://doi.org/10.1111/j.1750-3841.2010.01866.x

Choi, J. Y., Jin, Y. H., Yang, S. H., Lee, C. S., \& Huh, K. C. (2016). Quality and storage characteristics of yogurt containing Lacobacillus sakei ALI033 and cinnamon ethanol extract. Journal of Animal Science and Technology, 58, 16. https://doi.org/10.1186/s40781-016-0098-0

Duthie, G. G., Duthie, S. J., \& Kyle, J. A. M. (2000). Plant polyphenols in cancer and heart disease: implications as nutritional antioxidants. Journal of Nutrition, 13, 79-106. https://doi.org/10.1079/095442200108729016

Fernandez, J., Perez-Alvarez, J. A., \& Fernandez-Lopez, J. A. (1997). Thiobarbituric acid test for monitoring lipid oxidation in meat. Food Chemistry, 59(3), 345-353. https://doi.org/10.1016/S0308-8146(96)00114-8

García-Pérez, F. J., Lario, Y., Fernández-López, J., Sayas, E., Pérez-Alvarez, J. A., \& Sendra, E. (2005). Effect of orange fiber addition on yogurt color during fermentation and cold storage. Color Research \& Application, 30(6), 457-463. http://dx.doi/10.1002/col.20158

Hyo, J. N., Hye, M. S., Jun, H. L., \& Yoon, H. C. (2013). Physicochemical and sensory properties of yogurt supplemented with corni fructus during storage. Preventive Nutrition and Food Science, 18(1), 45-49. https://doi.org/10.3746/pnf.2013.18.1.045

Kim, W. S., Ren, J., \& Dunn, N. W. (1999). Differentiation of Lactococcus lactis subspecies lactis and subspecies cremoris strains by their adaptative response to stresses. FEMS Microbiology Letter, 171, 57-65. https://doi.org/10.1111/j.1574-6968.1999.tb13412.x

Kong, J. M., Chia, L. S., Goh, N. K., Chia, T. F., \& Brouillard, R. (2003). Analysis and biological activities of anthocyanins. Phytochemistry, 64, 923-933. http://dx.doi/10.1016/S0031-9422(03)00438-2

Kurmann, J. A. (1984). Aspects of the production of fermented milks. In Bulletin no.179, Fermented Milks, 16-26. Belgium, Brussels: International Dairy Federation.

Lazze, M. C., Savio, M., Pizzala, R., Cazzalini, O., Perucca, P., Scovassi, A. I., \& Bianchi, L. (2004). Anthocyanins induce cell cycle perturbations and apoptosis in different human cell lines. Journal of Carcinogenesis, 25, 1427-1433. http://dx.doi/10.1093/carcin/bgh138

Manach, C., Mazur, A., \& Scalbert, A. (2005). Polyphenols and prevention of cardiovascular diseases. Current Opinion in Lipidolology, 16, 77-84. Retrieved from https://www.ncbi.nlm.nih.gov/pubmed/15650567

Massa, S., Altieri, C., Quaranta, V., \& Pace, R. D. (1997). Survival of Escherichia coli 0157:H7 in yogurt during preparation and storage at 4 degree C. Letters in Applied Microbiology, 24(5), 2374-2385. https://doi.org/10.1046/j.1472-765X.1997.00067.x

Nayla, A., Gilani, A. H., \& Naheed A. (2008). Assessment of the quality of conventional yogurt as affected by storage. Pakistan Journal of Agricultural Sciences, 45(2), 218-222.

Retrieved from http://www.pakjas.com.pk/papers/186.pdf

Ogwaro, B. A., Gibson, H., Whitehead, M., \& Hill, D. J. (2002). Survival of Escherchia coli 0157:H7 in traditional African yogurt fermentation. International Journal of Food Microbiology, 79(1-2), 105-112. htt://doi.org/10.1016/S0168-1605(02)00184-8

Reineccius, G. (2006). An overview of flavor perception. Flavor chemistry and technology (2nd ed.). Florida, FLA: Boca Raton: Taylor and Francis.

Routray, W., \& Mishra, H. N. (2011). Scientific and technical aspects of yogurt aroma and taste: A review. Comprehensive Reviews in Food Science and Food Safety, 10, 208-220. https://doi.org/10.1111/j.1541-4337.2011.00151.x

Shah, N. P. (2000). Functional cultures and health benefits. International Dairy, 17(11), 1262-1277. https://doi.org/10.1016/j.idairyj.2007.01.014

Shah, N. P. (2000). Probiotic bacteria: selective enumeration and survival in dairy foods. Journal of Dairy Science, 83, 894-907. https://doi.org/10.3168/jds.S0022-0302(00)74953-8

Statistic. (2016). Statistics and facts on the yogurt market in the U.S. Retrieved from https://www.statista.com/topics/1739/yogurt/

Statistical Analysis Software (SAS). (2003). SAS User’s Guide Version 9.1.3. North Carolina, NC: Cary. 
Tamime, A. Y., \& Deeth, H. C. (1980). Yoghurt: Technology and Biochemistry. Journal of Food Protection, 43, 939-977. https://doi.org/10.4315/0362-028X-43.12.939

Tamime, A. Y., \& Robinson, R. K. (1985). Yoghurt science and technology. Pergamon Press Ltd., Oxford.

Tamime, A. Y., \& Robinson, R. K. (2007). Yoghurt science and technology (3rd ed.). Cambridge, Abington: Woodhead Publishing Ltd.

Tarladgis, B. G., Watts, B. M., Younathan, M. T., \& Jr. Dugan, L. (1964). Chemistry of the 2-thiobarbituric acid test for determination of malonaldehyde in rancid foods. Journal of the American Oil Chemists' Society, 37, 44-48. https://doi.org/10.1007/BF02633347

Wang, B., Pace, R. D., Dessai, A. P., Bovell-Benjamin, A., \& Phillips, B. (2002). Modified extraction method for determining 2-thiobarbituric acid values in meat with increased specificity and simplicity. Journal of Food Science, 67(8), 2833-2836. https://doi.org/10.1111/j.1365-2621.2002.tb08824.

\section{Copyrights}

Copyright for this article is retained by the author(s), with first publication rights granted to the journal.

This is an open-access article distributed under the terms and conditions of the Creative Commons Attribution license (http://creativecommons.org/licenses/by/4.0/). 